\title{
Lovell Charts the Future
}

\section{by our Astronomy Correspondent}

ONE of the traditions of the Royal Astronomical Society is that the presidential address should be devoted to the astronomical speciality of the president, but in a departure from convention last week Professor Sir Bernard Lovell spoke not on radio telescopes but on "The Prospects for British Astronomy", although some would say that an eye on the future also happens to be one of Sir Bernard's specialities. The occasion was the anniversary of the founding of the society 150 years ago, and Sir Bernard made clear that the celebrations have occurred at a crucial time for British astronomy. Since the war there has been a vast increase in the astronomy budget but this has brought important changes in the way British astronomy is run.

Sir Bernard cited the way the budget of the Astronomy, Space and Radio Board of the Science Research Council, which is responsible for almost all British astronomy, has risen from $20 \cdot 6$ per cent of the SRC budget in 1965-66 to about 25 per cent, or $£ 11.7$ million, now. He anticipated that by the mid 1970s the total annual budget of the SRC will have risen from its present $£ 46.8$ million to the region of $£ 63$ million, with the Astronomy, Space and Radio Board dealing with between $£ 15$ million and $£ 17$ million of that.

The share of ground-based astronomy might be expected to rise from its present $\mathfrak{£} 3$ million to $\mathfrak{£ 4}$ million in 1975, and Sir Bernard reminded the society that this would be equivalent to the amount needed for about fifty per cent of the shelved Whitford programme for the development of ground-based astronomy in the United States. Any exhilaration at these figures should be tempered by the knowledge that astronomers can no longer run their affairs in the old way. They must now be prepared to spend more time on the committees of the SRC because if there is no policy, and no united front among astronomers, then the growth rate of astronomy will fall.

The address concentrated on observational astronomy, and Sir Bernard said this is where the financial and organizational weakness lies-theoretical astronomy is by comparison well nourished with money and talent. There was also a tinge of sadness that the role of the society in the running of British astronomy has diminished, officially at least. "The new radio telescope at Cambridge will be managed and directed by Sir Martin Ryle and the University of Cambridge on behalf of the SRC. If our Mark $V$ radio telescope is ever built, this too will remain SRC property." The same goes for the optical telescopes, and although the Isaac Newton telescope is located at and maintained by the Royal Greenwich Observatory, its programme is essentially controlled by the Large Telescope Users Panel.

With the building of the 150-inch Anglo-Australian telescope at Siding Spring, the major British interest in the southern hemisphere is bound to shift from South Africa to Australia, Sir Bernard said. An urgent problem is to make sure that British astronomers are able to make full use of their half-share of the time on the 150-inch, and an admirable solution would be the establishment of a British supporting unit at Siding Spring equipped, for example, with a 48-inch Schmidt. This would do for the southern skies what the Palomar
Schmidt has accomplished in the northern hemisphere.

The problems of northern hemisphere astronomy centred on the UK are altogether more intractable, Sir Bernard said. "We have to develop advanced instrumentation, and that for use with the AngloAustralian telescope is already becoming an urgent matter. We must stimulate the university astronomy departments to teach and train astronomers and we must provide UK observational facilities in the northern hemisphere under the best European seeing conditions to match those which we are developing in the south. Finally we must devise an organization for using the telescopes and directing the money which $\mathrm{SRC}$ may be able to provide to the appropriate research groups in the universities and elsewhere." The solutions to these urgent problems have to be based on what Sir Bernard called the somewhat incoherent structure of British astronomy in the northern hemisphere, founded on two royal observatories, one with a telescope still small by world standards working under sky conditions which are far from ideal, and several university departments heavily dependent on the SRC.

STAMP CORNER

\section{RAS Commemorative}

The black-and-white print released by the Post Office fails to do justice to the $1 s 9 d$ stamp which will be on sale from April 1 to celebrate the 150th anniversary of the founding of the Royal Astronomical Society in 1820. Designed by Marjorie Saynor, a freelance designer making her first venture into stamp design, the stamp shows from left to right Sir William Herschel, Francis Baily (of Baily's beads fame) and Sir John Herschel against a delightful pink background. The telescope represents the reflector completed by William Herschel at Slough in 1789 which apparently was never a technical success because of mounting problems. But the inclusion of Herschel's telescope is appropriate because it features on the seal of the society.

A first-day cover service is being provided by the Royal Astronomical Society at a cost of $6 s 6 d$. For $17 s 6 d$, however, the deal includes an authentic signature of the president, and Sir Bernard Lovell claims to have made $£ 40$ for the society already.

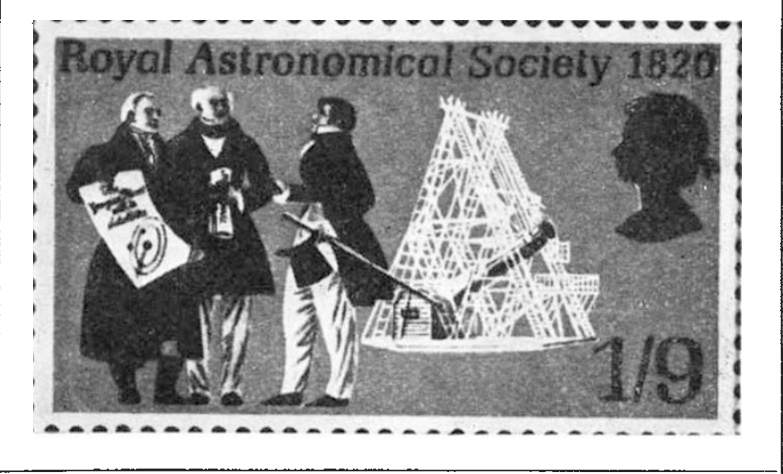

